13. Explained Desk. How countries are dealing with the surge in domestic violence under COVID-19 lockdown. Indian Express. 2020 Apr 6 [cited 2020 Apr 14]. Available from: https://indianexpress.com/article/ explained/how-countries-are-dealing-with-the-surge-in-domesticviolence-under-covid-19-lockdown-6350186/

14. Gearin M. Knight B. Family violence perpetrators using COVID-19 as a 'form of abuse we have not experienced before'. ABC News. 2020 Mar 29[cited 2020 Apr14]. Available from: https://www.abc net.au/news/2020-03-29/coronavirus-family-violence-surge-invictoria/12098546

15. World Health Organisation, London School of Hygiene and Tropical Medicine, and South African Medical Research Council. Global and regional estimates of violence against women: prevalence and health effects of intimate partner violence and nonpartner sexual violence. 2013 Mar; WHO, LSHTM, SAMRC; 2013[cited 2020 Apr 14]. Available from: https://apps.who.int/iris/bitstream/handle/10665/85241/WHO_ RHR_HRP_13.06_eng.pdf;jsessionid=3780B91D03A6CDBAD9BA4606 7B533FB3? sequence $=1$

16. Golder S.Measurement of domestic violence in NFHS surveys and some evidence.Oxfam India; 2018 [cited 2020 Apr 14]. Available from:https:// www.oxfamindia.org/sites/default/files/2018-10/WP-Measurementof-Domestic-Violence-in-National-Family-Health-Survey-surveys-and-
Some-Evidence-EN.pdf; p-4

17. PTI. Lockdown turns into captivity for women. Telegraph. $2020 \mathrm{Mar}$ 31[cited 2020 Apr 14]. https://www.telegraphindia.com/india/ lockdown-turns-into-captivity-for-women/cid/1760856

18. Sirur S, Krishnan R. Indian women are locked in with their abusers, but are finding new ways to seek help. Print. 2020 Apr 3[cited 2020 Apr 14]. Available from: https://theprint.in/india/indian-women-are-locked-inwith-their-abusers-but-are-finding-new-ways-to-seek-help/393949/

19. Chandra J. Covid-19 lockdown: rise in domestic violence, police apathy: NCW. Hindu. 2020 Apr 2[cited 2020 Apr 14]. Available from: https:// www.thehindu.com/news/national/covid-19-lockdown-spike-indomestic-violence-says-ncw/article31238659.ece

20. Bose A. India's domestic abuse survivors are in lockdown with their monsters, but helplines are not ringing. News 18.2020 Apr 6 [cited 2020 Apr 14]. Available from: https://www.news18.com/news/buzz/indiasdomestic-abuse-survivors-are-in-lockdown-with-their-monsters-butthe-helplines-are-not-ringing-2563955.html

21. Business Today. Coronavirus lockdown: WHO says domestic violence on rise, asks nations to take measures. 2020 Apr 5 [cited 2020 Apr 14]. Available from: https://www.businesstoday.in/latest/trends/ coronavirus-lockdown-who-says-domestic-violence-on-rise-asksnations-to-take-measures/story/400191.html

\title{
The Covid-19 pandemic and India's cardiovascular disease burden: Finding the right balance
}

\section{MEGHANA CHALASANI, KHURRAM NASIR, MOHIT D GUPTA, ANKUR KALRA}

\section{Abstract}

The national lockdown in India has (thus far) prevented a surge of Covid-19 cases. Due to crowded living conditions and poor social security, infectious spread may be difficult to contain and mitigate. India's healthcare system must respond to impending Covid-19 cases, as well as chronic, non-communicable diseases. Acute and chronic cardiovascular disease care have drastically decreased, suggesting reduced accessibility during the current pandemic. Neglecting chronic diseases may lead to permanent health damage and deaths that far exceed the negative outcomes of the pandemic alone. As businesses start to reopen, the healthcare system must find a balance in attending to Covid-19 rises amidst a significant chronic disease backdrop.

Authors: Meghana Chalasani (mchalasani@neomed.edu), Section of Cardiovascular Research, Heart, Vascular and Thoracic Department Cleveland Clinic Akron General, Akron, Ohio, USA; Khurram Nasir (knasir@ houstonmethodist.org), Division of Cardiovascular Prevention and Wellness, Houston Methodist DeBakey Heart \& Vascular Center Center for Outcomes Research, Houston Methodist, Houston, Texas, USA; Mohit D. Gupta (drmohitgupta@yahoo.com), Govind Ballabh Pant Hospital, New Delhi, INDIA; Ankur Kalra (corresponding author - kalraa@ccf.org), Department of Cardiovascular Medicine, Heart, Vascular and Thoracic Institute, Cleveland Clinic, Cleveland, Ohio, USA

To cite: Chalasani M, Nasir K, Gupta MD, Kalra A. The Covid-19 pandemic and India's cardiovascular disease burden: Finding the right balance. Indian J Med Ethics. 2020 Jul-Sep; 5(3) NS: 199-201. DOI: 10.20529/IJME.2020.059.

Published online on May 15, 2020.

Manuscript Editor:Vijayaprasad Gopichandran

(c) Indian Journal of Medical Ethics 2020
Keywords: India, Covid-19, cardiovascular disease, pandemic

\section{Background}

While the epicenters of the coronavirus disease 2019 (Covid-19) pandemic remain in the United States and Europe, concern for spread in developing countries should not be blind-sighted. Many Southeast Asian countries have a myriad public health concerns atop an impending infectious disease. On March 24, 2020, the Prime Minister of India, Mr Narendra Modi announced a national lockdown that has been extended until May 17, 2020, with different regulations based on regional viral spread (1). Physical distancing may not be feasible in a country with triple the population of the United States within one-third of the physical space, as well as fewer homeowners and less social security coverage. Although poverty in India is declining, $22 \%$ of Indian citizens lived below the poverty line of $\$ 1.25$ in 2011-2012, according to the United Nations Millennium Development Goals Programme (2). According to the Indian Ministry of Statistics and Programme Implementation, per-capita monthly income during 2019-2020 is estimated to be Rs. 11,254 , or about $\$ 150$ (3).

Further compounding these challenges, it is important to remember that the workforce of India does not experience the same protections and support that Western nations have adopted (4). India's employment-based plan for social security is limited to business units employing a minimum number of employees. In the economic census of 2013-2014, it was reported that $98.6 \%$ of all establishments employed less than ten workers (4). Most of these individuals do not have social 
security or health coverage. However, even workers covered by the Employees' State Insurance (ESI) do not have sufficient coverage with facilities and staff in the medical infrastructure. In preparation for Covid-19 treatment, the government plans to set aside $15 \%$ of ESI beds for isolation cases, debilitating care for other diseases during this time (4). The abrupt national shutdown has placed the responsibility for containment and mitigation on citizens of India without a support system (5).

\section{Cardiovascular and non-communicable diseases in India}

While infectious diseases have historically been believed to affect underdeveloped or poverty-stricken nations, we have learned that no country is exempt from a pandemic (6). In the current era, with the rapid trajectory of Southeast Asian countries emerging from being "developing nations," there is a double-threat from a shift in disease patterns of both infectious and chronic conditions. For example, in India, noncommunicable diseases, including cardiovascular diseases, cancer, chronic respiratory diseases, and diabetes have surpassed communicable diseases as the leading cause of death (7).

Deprioritisation of chronic disease care in India during a pandemic will have a domino effect on the overall health and wellbeing of the population. While the immediate healthcare system focus remains on controlling the Covid-19 pandemic, we caution policy makers to ensure that chronic disease care in India during a pandemic is not ignored. Cardiovascular diseases make up a substantial portion of non-communicable diseases that cause mortality and pose economic burdens in India. In 2016, about 62.5 million-years of life were prematurely lost in India as a result of cardiovascular diseases (8). The continuing trend of increased cardiovascular disease affliction and mortality is partially attributable to significantly greater dietary risks in India (8). The life-threatening emergencies, including myocardial infarction and stroke, that accompany cardiovascular diseases are reason for concern in the current climate. During the uncertain times of this pandemic, we are concerned that essential and nonessential chronic disease management will be significantly jeopardised, and those afflicted with chronic diseases such as CVD, will receive inadequate care. The ambiguous area of defining essential care will likely leave patients who would benefit from care with a compromised quality of life either temporarily or permanently.

The current goal should be to provide the best possible healthcare in the current time of crisis, rather than focusing only on Covid-19 patients. Routine health services must be ensured so that patients do not suffer the consequences of inaction. Accordingly, the Ministry of Health and Family Welfare (MOHFW) of the Government of India has published guidelines for states regarding the provision of health services during this pandemic (9). Essential health services, apart from Covid-19 hospitalisations, include treatment for chronic diseases, management of communicable diseases, and emergency, reproductive, maternal, new-born, and child health care. In order to achieve an optimal duality of services, healthcare centers should be designated as Covid-19 facilities or non-Covid-19 facilities; the latter will continue to provide essential health services (9). Telehealth is valuable to triage different patients, without contact. For example, a helpline will differentiate concerns of suspected Covid-19 patients and those with new medical needs, and direct individuals to a Covid-19 or non-Covid-19 facility (9). Those with regular care services should continue treatment at a non-Covid facility or via telemedicine. Guidelines for appropriate use of telemedicine and face-to-face visits for non-Covid-19 patients may be defined according to specialty or disease at a state or network level. Ghosh et al have provided a framework for diabetes care that includes general rules with video health conferencing, acquisition of medical histories, virtual examination, etc, specifying cases that will require face-to-face consultations, such as new patients for treatment initiation, and emergencies (10). Although telemedicine lacks physical examination, virtual health appointments can confer many benefits to mitigate viral spread and provide continuity of care.

The Government of India also advises states to identify essential services and engage with the private health sector to augment capacity and resources. For non-communicable diseases, the MOHFW suggests medication supply for up to three months for non-communicable diseases including diabetes and hypertension (9). States of India have taken proactive measures by integrating information as it becomes available locally and globally. The GEM Patient Safety Initiatives (GPSI) were formulated in the private sector and have been in use across Tamil Nadu and Kerala (11). Preventive safety measures are outlined to include unidirectional flow within centres, segregation of visitors, sanitisation, information dispersal, etc (11). These functions allow simultaneous care for non-Covid-19 conditions during the pandemic. Networks and states should work toward development of organised frameworks that adequately serve all patients. Non-essential procedures may be deferred for the time being, but patients may also experience fear of infection that changes their decisions to present for chronic diseases and undergo care (12). Covid-19 introduces a daunting novel consideration in care plans for patients and physicians alike.

\section{Treatment accessibility for chronic disease}

The National Health Mission reported available data on healthcare facilities' provision of health services (13). Many services, including inpatient and outpatient care, had decreased in March 2020 compared with February 2020, as well as March 2019. Outpatient treatment for diabetes, hypertension, stroke, acute heart diseases, and other noncommunicable diseases, including cancer and mental illness, vastly declined. Standardised data show an almost $30 \%$ decrease in reported acute cardiac emergencies and about 50\% decrease in outpatient heart disease care (13). Inpatient treatment for communicable diseases and number of emergencies were greatly curtailed as well. These data and 
experts suggest that reduced hospitalisation is a result of a lack of overall access rather than reduced illness (13). Chronic illness remains consistent over time and requires regular treatment. It should be understood that patients who would otherwise be routinely treated are foregoing healthcare services in the current climate. Without transportation and community services, healthcare has become less accessible, and accountability has decreased. It is probable that patients are falling ill or passing away in their homes, and that mortality data are likely underreported at this time. Avoiding treatment for non-Covid-19 illness is dangerous and unsustainable. India's healthcare system must move away from fears given that evasion will only lead to deterioration of the population due to chronic disease in the future.

As we progress through this pandemic that will most adversely impact the economic well-being of millions of families across the nation, it will also exacerbate inability to pay for healthcare services. In the absence of an established universal healthcare coverage, out of pocket expenditure remains the major source of financing for hospitalisation costs in India, and is estimated to exceed $10 \%$ of household consumption spending (6). A common practice in India to meet healthcare costs is distress health financing, which involves selling assets, borrowing money, and taking loans to care for sick family members. The two concepts are associated, as households that incur catastrophic health expenditure are more likely to engage in distress financing (6). Many families fall into debt or poverty after experiencing high hospitalisation costs and expenditures.

We hope that India's extended national lockdown to slow down infections will yield positive dividends. However, with challenges in enforcing prolonged and robust physical distancing, as well as lack of broad testing capacity, there is a strong possibility of widespread outbreak with significant unintended health consequences for those suffering from chronic conditions such as cardiovascular diseases. Considering that India's healthcare system that has insufficient investment in the public health sector, we are concerned that management will likely experience havoc with overwhelmed facilities, with the underprivileged likely to be most severely affected, especially related to much needed access to care. While India, like others, will have its owns successes and failures, it is critical that local health systems swiftly adopt best practices for containing pandemics from lessons learned by others, while pragmatically finding balance in maintaining the much required resources for management of chronic noncommunicable diseases.

\section{References}

1. ET Online. Lockdown extended by 2 weeks, India split into red, green and orange zones. Economic Times. 2020 May 1 [cited 2020 May 6]. Available from: https://economictimes.indiatimes.com/news/politics-andnation/govt-extends-lockdown-by-two-weeks-permits-considerablerelaxations-in-green-and-orange-zones/articleshow/75491935.cms

2. Mehra P. $8 \%$ GDP growth helped reduce poverty: UN report. Hindu. 2016 Apr 2 [cited 2020 May 6]. Available from: https://www.thehindu. com/news/national/8-gdp-growth-helped-reduce-poverty-un-report/ article6862101.ece

3. PTI. India's per-capita income rises $6.8 \%$ to Rs 11,254 a month in FY20. Business Today. 2020 Jan 7[cited 2020 May 6]. Available from: https:// www.businesstoday.in/current/economy-politics/india-per-capitaincome-rises-68-to-rs-11254-a-month-in-fy20/story/393333.html

4. Jha S. Migrant workers head home in coronavirus lockdown, exposed and vulnerable. Business Standard. 2020 Mar 26[cited 2020 May 6]. Available from: https://www.business-standard.com/article/economypolicy/coronavirus-lockdown-headed-home-as-migrants-have-noroom-to-isolate-120032501678_1.html

5. Krishnan, V. The callousness of India's COVID-19 response. Atlantic. 2020 Mar 27[cited 2020 May 7]. Available from: https://www.theatlantic.com/ international/archive/2020/03/india-coronavirus-covid19-narendramodi/608896/

6. Tandon, P. COVID-19: Impact on health of people \& wealth of nations. Indian J Med Res. 2020; 151(2): 121-3. doi:10.4103/ijmr.IJMR_664_20

7. Kastor A, Mohanty P. Disease-specific out-of-pocket and catastrophic health expenditure on hospitalization in India: Do Indian households face distress health financing? PLOS ONE, 2018 May 10;13(5): e0196106. doi:10.1371/journal.pone.0196106

8. Prabhakaran D, Singh K, Roth GA, Banerjee A, Pagidipati NJ, Huffman MD. Cardiovascular diseases in India compared with the United States.J Am Coll Cardiol. 2018 Jul 3; 72(1), 79-95. doi:10.1016/j.jacc.2018.04.042

9. Ministry of Health and Family Welfare. Enabling delivery of essential health services during the COVID 19 outbreak: Guidance note. New Delhi: MoHFW; 2020 [cited 2020 May 9]. Available from: https://www. mohfw.gov.in/pdf/EssentialservicesduringCOVID19updated0411201. pdf

10. Ghosh A, Gupta R, Misra A.Telemedicine for diabetes care in India during COVID-19 pandemic and national lockdown period: Guidelines for physicians. Diabetes Metab Syndr. 2020 Apr 3; 14(4):273-6. doi:10.1016/j. dsx.2020.04.001.

11. Asokan S. Private sector and patient safety. Hindu. 2020 Apr 29[cited 2020 May 8]. Available from: https:/www.thehindu.com/news/ national/tamil-nadu/expert-speak-private-sector-and-patient-safety/ article31467523.ece

12. Kittleson $M$. The invisible hand-medical care during the pandemic. $N$ Engl J Med. 2020, Apr 2. doi:10.1056/NEJMp2006607

13. Rukmini, S. How covid-19 response disrupted health services in rural India. Livemint. 2020 Apr 27[cited 2020 May 8]. Available from: https:// www.livemint.com/news/india/how-covid-19-response-disruptedhealth-services-in-rural-india-11587713155817.html 